\title{
Desenvolvimento Local e a expansão de empresas multinacionais. Discussão a partir de dois municípios de Mato Grosso do Sul, Brasil
}

\author{
Local Development and the expansion of multinational companies. Discussion \\ based on two municipalities of Mato Grosso do Sul, Brazil
}
Desarrollo Local y la expansión de empresas multinacionales. Discusión a partir de dos municipios de Mato Grosso do Sul, Brasil

\author{
Antonio Hilário Aguilera Urquiza ${ }^{1}$ \\ Josemar de Campos Maciel ${ }^{2}$
}

Recebido em 14/05/2018; revisado e aprovado em 18/03/2019; aceito em 08/04/2019

DOI: http://dx.doi.org/10.20435/inter.v0i0.1988

\begin{abstract}
Resumo: O presente estudo discute impactos da implantação de um empreendimento global agroalimentar, mediante investimento direto, em dois municípios do Sudeste de Mato Grosso do Sul. O ensaio utiliza entrevistas de campo e dados socioeconômicos. Aponta-se para a oportunidade de uma ideia de Desenvolvimento Local que fomente um tecido social participativo e autônomo diante dos desafios do mundo contemporâneo.
\end{abstract}

Palavras-chave: desenvolvimento; impacto; mobilização.

Abstract: The present essay shows some impacts of the implementation of a global agro-food enterprise in two municipalities in the South-east of Mato Grosso do Sul. The discussion uses field interviews and socioeconomic data to point to an idea of Local Development that fosters a participatory and autonomous social dynamics, able to face the challenges of the contemporary world.

Keywords: development; impact; mobilization.

Resumen: El presente estudio aborda los impactos de la implementación de una empresa agroindustrial global, a través de inversión directa, en dos municipios del Sudeste de Mato Grosso do Sul. La discusión usa entrevistas de campo y datos socioeconómicos. Se enfatiza la oportunidad de promover una dinámica social participativa y autónoma, capaz de enfrentar los desafíos del mundo contemporáneo.

Palabras clave: desarrollo; impacto; movilización.

\section{INTRODUÇÃO: TIPOLOGIA E SÍNTESE DO CASO - RELAÇÃO DO CASO COM O CONCEITO}

A representação do Desenvolvimento mais naturalizada no século XX é a de que os atores nacionais considerados mais desenvolvidos a partir dos parâmetros que eles mesmos constroem teriam se alçado a um patamar superior de evolução, podendo ajudar, com isso, os menos desenvolvidos a se postarem de forma positiva diante do cenário das trocas de um mundo comercial supostamente neutro (EISENSTADT, 1973; PEET; HARTWICK, 2015, p. 138). Essa representação desembocou em modelos de desenvolvimento que abraçam dinâmicas de engenharia macrossocial e ambiental de estilo top-down, que sobrevoam interesses e necessidades de atores territoriais e a preocupação pela sustentabilidade, ou pelo menos as relegam a uma função secundária, privilegiando as funções especulativas do "mercado" (BRESSER-PEREIRA, 1997; PEET; HARTWICK, 2015).

Noutra direção, inspirando a elaboração de conceitos, agendas e práticas na escuta de vocalidades, territorialidades, paisagens e proxemias, dirigem-se propostas residuais, às vezes

\footnotetext{
${ }^{1}$ Universidade Federal de Mato Grosso do Sul, Campo Grande, Mato Grosso do Sul, Brasil.

${ }^{2}$ Universidade Católica Dom Bosco, Campo Grande, Mato Grosso do Sul, Brasil.
} 
denominadas de "Desenvolvimento Local" (ÁVILA, 2006; DOWBOR, 2016; BELLINGIERI, 2017). Uma das variantes dessas formas de reflexão esforça-se por mostrar atravessamentos nas discussões, gerados por condições e relações de subalternidade, na construção das tramas de relações entre localidades desarticuladas e centros mais industrializados e militarizados (RAFFER, 1987; VALENCIA, 2017; MIGNOLO, 2012). O texto que se segue é uma elaboração a partir de um encontro com essas condições, discutindo aspectos da entrada de uma empresa multinacional no horizonte de duas pequenas cidades do Estado de Mato Grosso do Sul. Não se espante o leitor, mas o que se segue é um ensaio, figura constante na literatura de todas as áreas. Requer atenção, pois, e é o oposto de uma série de equações visando a um planejamento barato e sem subjetividade. Aqui defendemos o contrário: a erosão da subjetividade enseja encontros que não interessam aos pequenos atores que tentam sobreviver.

Os dados são sobretudo sociodemográficos e econômicos, secundados por considerações resultantes de entrevistas, visitas e percepções derivadas de contato direto. Adota-se a perspectiva das municipalidades, enquanto elas se interrogam acerca da sua própria iniciativa. O esforço teórico é o de entender um fenômeno, a saber: o encontro entre duas formas de experiência, territorial e humana, que produziu alguns elementos que serão mostrados e comentados, para gerar um quadro interpretativo para o caso em epígrafe. Todo o texto parte da afirmação de que a pervasividade da simetria em relações de troca, axioma ainda sustentado por autores que discutem o desenvolvimento (PIETERSE, 2000), não se sustenta diante de relações de saber-poder, em que uma das partes é hipossuficiente (PFETSCH; LANDAU, 2000).

\section{ENCONTRANDO O DESENVOLVIMENTO}

O caso em questão é o encontro entre escalas ${ }^{3}$ diversas de ação e de territorialidade. Duas cidades são colhidas em um movimento que as torna interlocutoras de outros ritmos, mais amplos que elas. De certa forma, encontram o desenvolvimento (ESCOBAR, 1995) na sua forma mais comum, a da aceleração do crescimento na acumulação. Na posição mais ampla do espectro imaginário, encontra-se uma empresa de capital aberto, a Adecoagro. Num ponto intermediário, duas municipalidades do interior do Estado de Mato Grosso do Sul, de estrutura social ligada a uma matriz de produção econômica agrícola e agrária. E, na terceira posição, encontramos a população.

O processo é deflagrado quando a empresa adquire terras mediante investimento direto nos dois municípios, para consolidar e facilitar suas atividades. Parte dessas ações é ligada ao tratamento industrial do plantio de cana-de-açúcar, na relação direta com a terra e o ambiente rural; outra parte abrange investimentos em Bolsa de Valores, em escala internacional (FREITAS; ROSSINI; QUEIRÓZ, 2014). A empresa é aqui a escala mais alta porque é transnacional por natureza. Além de dedicar-se à plantação de cana, situando-se no mercado como agroindústria,

\footnotetext{
${ }^{3}$ Entenda-se aqui "escala" em um sentido argumentativo. Em sentido de discurso como parte da construção de realidades, uma escala é formada por argumentadores com interesses e vocabulários relativos. Em sentido político, é uma trama de mecanismos simbólicos em tensão e interação. Em sentido territorial, um conjunto de circuitos, de proxêmicos a formais, que trocam informações através de instituições. A análise das ideias a partir de escalas aqui segue de perto a "análise política do discurso", como proposta por Isabella e Norman Fairclough (2012), em que a agência de Weber encontra-se com a simbolização da antropologia, ambas atravessadas pela teoria política. Sem seguir passo a passo a análise, ressalta-se o pressuposto de que a linguagem é performativa, ou seja, não se consideram sujeitos anteriormente à linguagem. Pelo contrário, a comunicação constrói ambas as realidades. Uma leitura mais geográfica e crítica do debate encontra-se em Herod (2011).
} 
é também empresa de capital aberto, não apenas participando do movimento de globalização financeira, mas capitaneando parte dele, desde o seu principal acionista, George Soros. Noutros termos, aqui se nota e se comenta apenas parte de uma iniciativa muito mais ampla de acumulação e de construção de uma rede globalizada (VON RÉTYI, 2016; ROSA, 2013; SAUER; LEITE, 2012; SILVA FILHO, 2015).

A Adecoagro apresenta-se no Brasil, em sua página oficial (http://www.adecoagro.com/ home.aspx), como uma empresa especializada em produção de alimentos e energia renovável. Entre os alimentos, destacam-se arroz, açúcar, leite, girassóis, milho, trigo e soja, produzidos de forma intensiva; entre as energias renováveis, energia elétrica e etanol. A empresa iniciou as atividades em 2002, entrando na Argentina e, em seguida, Uruguai e Brasil. Sua missão declarada é "liderar a produção de alimentos e energia renovável, oferecendo aos investidores e acionistas uma alternativa de investimento atrativa, estável, líquida e confiável". Ela deixa clara sua intenção de mediar entre o mercado de investimentos e as novas ruralidades ${ }^{4}$. Apresenta-se, assim, na dinâmica da expansão que reconfigura as territorialidades de países do Sul a partir das prioridades de investimento do mercado financeiro (BOWEN, 2014; DÖRRE, LESSENICH; ROSA, 2015).

Sendo ainda uma empresa multinacional de capital aberto, na tentativa de atender à demanda discursiva por um compromisso com a retórica da sustentabilidade, a empresa propôs uma pesquisa analisando o seu impacto nos dois municípios em que atua mais diretamente, as cidades de Angélica e Ivinhema, no Estado de Mato Grosso do Sul (IBGE, 2018a; 2018b). A maior parte dos dados empíricos deste texto é oriunda dessa pesquisa, desenvolvida por um grupo ligado à Universidade Federal de Mato Grosso do Sul (AGUILERA URQUIZA, 2014). A pesquisa, interdisciplinar, envolveu levantamentos de diversos dados a partir de fontes oficiais. Foram realizadas também entrevistas, com três tipos diferentes de envolvidos no processo: empreendedores, funcionários e moradores dos municípios. Estes três tipos de interlocutores servem para avalizar a divisão em três escalas propostas como parte do quadro categorial para a construção do trabaIho. As informações quantitativas dos municípios podem ser acompanhadas na página do IBGE (IBGE, 2018a; IBGE, 2018b) e estão estabilizadas no padrão aqui reportado. Angélica e Ivinhema tornaram-se municípios na mesma dinâmica discursiva da construção do Estado desenvolvimentista, a "Marcha para o Oeste", tentativa do Governo Federal de realizar a integração dessa Região no contexto nacional. Isso envolveu a participação de uma força-tarefa para um planejamento político de grande escala (PEREIRA, 1997; KLEVER, 2016). Envolveu também a participação de diversos grupos de participantes, com a adesão de cientistas (VILLAS BÔAS; VILLAS BÔAS, 2012). Como outros municípios de outros Estados da região Centro-Oeste do Brasil, eles compõem um esforço que deflagra um movimento de decolagem, no âmbito de práticas de desenvolvimento.

\section{PREÇO DA ACELERAÇÃO}

A pesquisa chama a atenção para alguns dados que conectam elementos sociodemográficos, indicadores econômicos e narrativas de desenvolvimento. É notável o clima de aceleração nos indicadores dos dois municípios, com a instalação da Adecoagro (AGUILERA URQUIZA, 2014, p. 28-31). Angélica viu um crescimento de $1.090 \%$ na atividade industrial, desde a implantação da Indústria. O crescimento de Ivinhema foi menor, mas, mesmo assim, permaneceu significativo, alcançando a marca de $175 \%$. Outros indicadores podem ser visualizados abaixo.

\footnotetext{
${ }^{4}$ Cf. http://www.adecoagro.com/DinamicPage.Aspx?midpid=2\&mimid=1\&miid=91. Acesso em: 21 de fev. 2018
} 
Figura 1 - Indicadores de Crescimento de Angélica e Ivinhema, MS, de 1999 a 2011

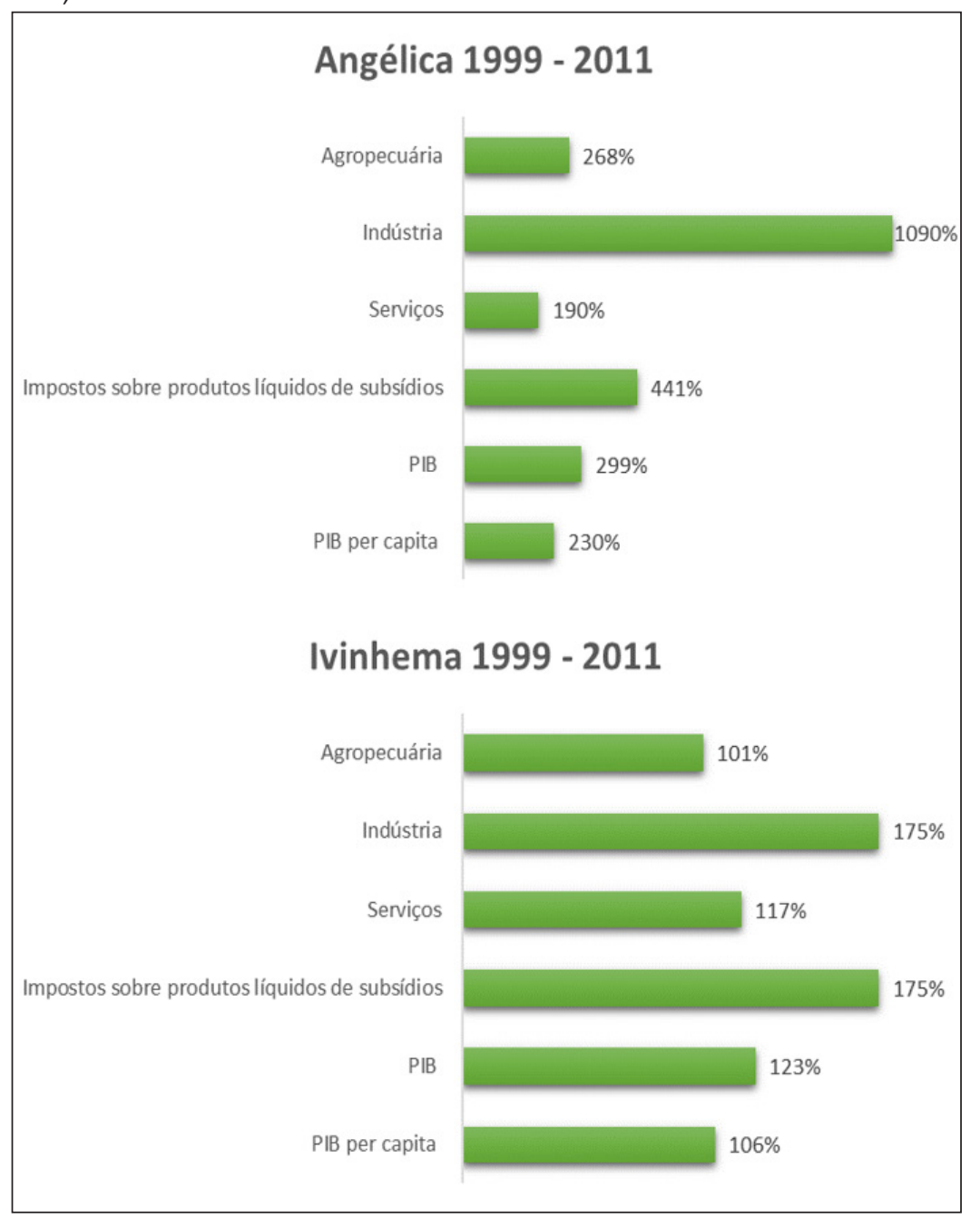

Fonte: AGUILERA URQUIZA (2014, p. 30).

Praticamente todos os indicadores macroeconômicos apontam para aceleração - como o PIB, a Renda Per Capita e a Renda Bruta dos Municípios. Isso confirma a ideia de que em certos casos importantes a aceleração de atividades nos territórios acompanha iniciativas normalizadas pelo senso comum como sendo de desenvolvimento. Mas essa aceleração não é automaticamente positiva para os territórios, no sentido da experiência de sustentabilidade ou de justiça social. Quando a aceleração encontra esses indicadores de mudança tão acentuada, a literatura aponta para um possível esgarçamento que cria vulnerabilidades no campo do tecido social e cultural (ROSA, 2013; BRASSIER, 2014). De modo desigual, mas em ambos os municípios, a entrada do ator de grande escala alterou o balanço das atividades. A participação dos setores econômicos no PIB modificou-se, desequilibrando o balanço pelo reforço da participação da indústria na composição do quadro. O aumento dos indicadores, em termos absolutos, pode ser um indicador positivo, mas deixa a pergunta sobre ser um aumento equilibrado, se ambas as cidades conseguem contribuir de forma sustentável com essa aceleração. Se não conseguem, aponta-se para um movimento de esgarçamento. 
Figura 2 - Indicadores de Crescimento de Angélica e Ivinhema, MS, de 1999 a 2011

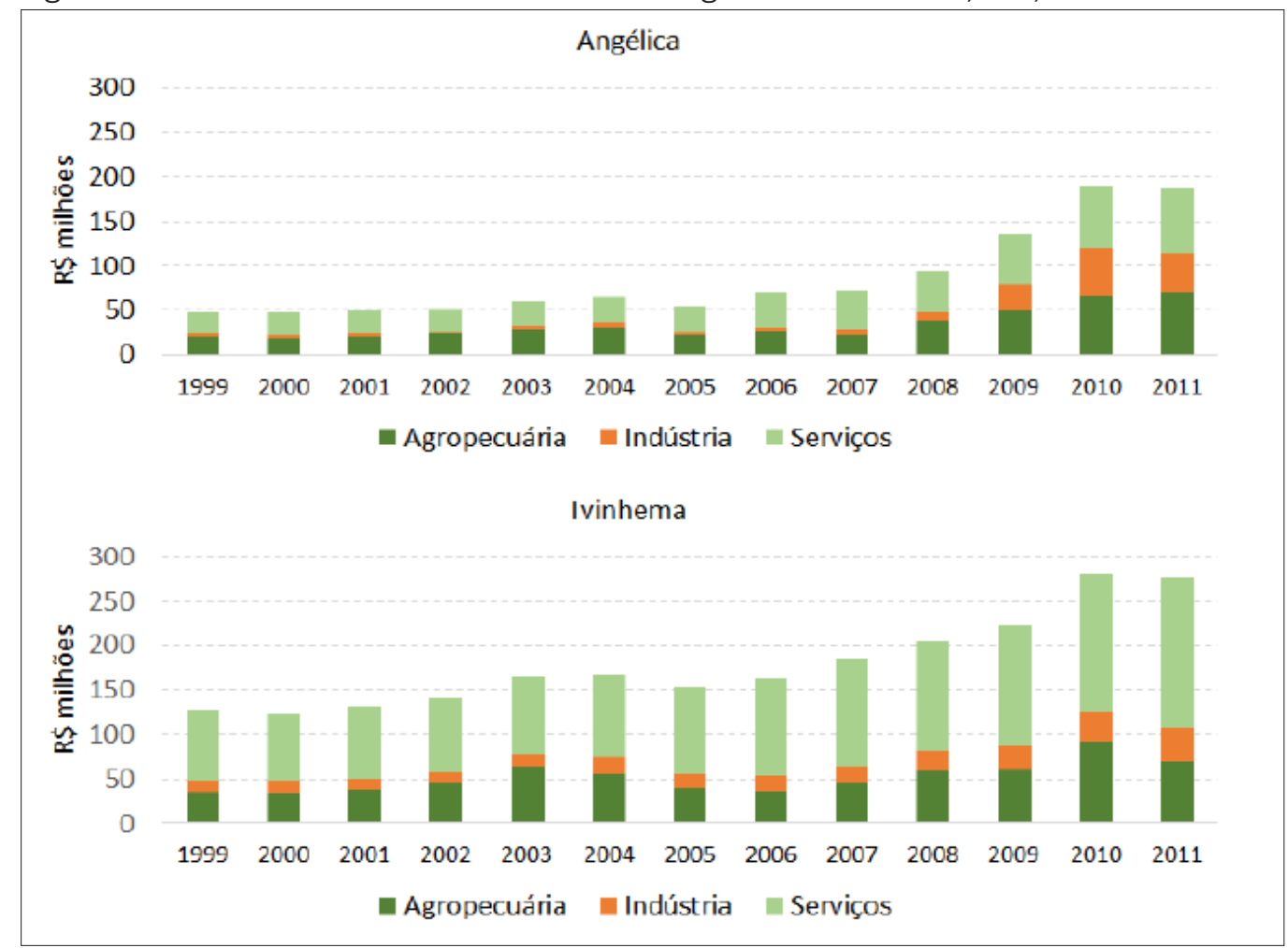

Fonte: AGUILERA URQUIZA (2014, p. 32).

Em uma investigação atenta, há de interrogar-se quanto da aceleração da atividade industrial está composto a partir de uma alteração também significativa no tecido produtivo social. Ou seja, quanto da população local está se apropriando das atividades que estão alterando seu sistema de vida e de produção. Essa interrogação pode ser entendida a partir do cruzamento com dois indicadores: o sistema do trabalho e o da produção/circulação qualificada de conhecimentos.

Figura 3 - Empregos diretos gerados pelo empreendimento ADECOAGRO em ambos os municípios

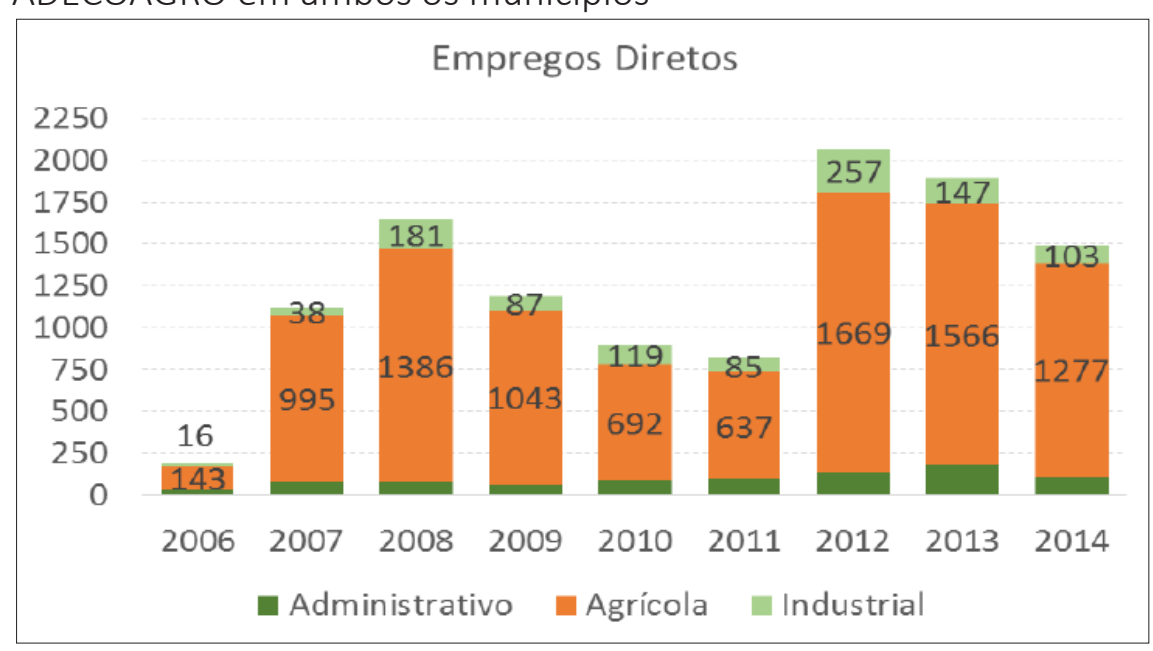

Fonte: AGUILERA URQUIZA (2014, p. 37). 
No gráfico, nota-se como o aumento de atividades está sendo impulsionado por um crescimento em setores que exigem trabalho menos qualificado do que seria o caso, por exemplo, de setores relacionados ao planejamento de aspectos da agenda do empreendimento. Ou seja, o trabalho que aumenta é subalterno e dependente das atividades-matriz (HARRISON, 2010; MATHUR, 2016; MIGNOLO, 2012; FRANK, 1969). O empreendimento traz benefícios, impactando diversos setores, tais como produção agrícola, mão de obra, consumo de energia, empregos indiretos, impostos, geração de renda e assim por diante. Também aumenta o fluxo de capital para os recursos do ator político-administrativo, mediante os impostos recolhidos pela empresa. O principal imposto é parte do ICMS, permanece nos municípios para que eles respondam ao empreendimento, criando uma rede de infraestrutura que o localize. Como a concentração maior da criação de empregos diretos é na área agrícola, pode-se inferir que o processo de impacto na geração de indicadores positivos não é seguido de perto pelo enraizamento da empresa no contexto territorial. O principal ponto que permite essa inferência é a relação com os indicadores de escolaridade e sua capilarização - que daria conta da circulação qualificada de informações e conhecimentos. Nenhum dos dois municípios possui estabelecimentos de ensino superior. Ou seja, o giro de mão de obra não atinge, de forma sustentada, camadas mais lidas da população local. A capilarização acontece mais lentamente do que a surpreendente aceleração (AGUILERA URQUIZA, 2014; IBGE, 2018a; IBGE, 2018b). Noutros termos, as duas cidades manifestam faIhas para potencializar o impacto do empreendimento, tornando-se dependentes. $O$ hiato nas estruturas de capilarização aparece em três níveis.

Primeiramente, no tecido social. A chegada e a instauração de uma iniciativa que provoca a reconfiguração da territorialidade implicam em encontrar um posicionamento favorável das municipalidades em relação à aceleração do empreendimento. Angélica e Ivinhema são menos articuladas do que uma megaempresa que opera em escala nacional na indústria sucroalcooleira (FREITAS; ROSSINI; QUEIRÓS, 2014).

Em segundo, na representação dos entrevistados. Uma amostra da população foi entrevistada, respondendo a diversas perguntas acerca do sistema de vida e suas condições materiais, de infraestrutura, para produzir uma ponte entre a empresa e o poder público. E essa ponte é exatamente a percepção dos cidadãos. A percepção geral é a de que não há um bom relacionamento entre o agente que traz recursos e a administração local, que os gere - no que tange à relação entre o empreendimento e itens de infraestrutura, como iniciativas de saúde, educação e erradicação da pobreza. Ou seja, existe uma percepção de falha na articulação entre as duas escalas - a da empresa e a das autoridades públicas. Isso pode indicar diversos fatores que enviesariam uma conclusão mais ampla. De todo modo, a existência de uma percepção negativa em relação ao nível das autoridades e de sua função na aplicação de recursos aponta para uma falha de comunicação.

O terceiro nível de dificuldade com as estruturas de capilarização é a relação institucional entre o empreendimento e as iniciativas locais. De toda a pesquisa, talvez o dado mais claro seja a inexistência de iniciativas de natureza pública de ensino superior nos dois municípios. Mesmo havendo grande taxa de crescimento de renda e de circulação de oportunidades, a ausência de oportunidades de qualificação sustentável mostra a subalternização das municipalidades ao ator externo. Consequentemente, mostra ainda um hiato nas estruturas de institucionalização para a maior qualificação e competitividade do território, como preconiza a teoria que entende o Desenvolvimento Local como uma forma de articulação (BARQUERO, 2002; DOWBOR, 2016; 
BELLINGIERI, 2017). Não existe um mecanismo efetivo de apropriação do conhecimento a partir das cidades. Pelo contrário, a empresa entra no Brasil apropriando-se de parte das iniciativas e das estruturas já existentes, de exploração e beneficiamento da cana para a geração de energia e combustível. Ocorre um conflito de interesses quanto à produção, circulação e elaboração de conhecimentos. Para a indústria e o mercado financeiro, grandes categorias aqui envolvidas, o conhecimento é estratégico e deve ser protegido como diferencial competitivo (VALLEJOALONSO; RODRÍGUEZ-CASTELLANOS; ARREGUY-AVASTUY, 2011). Para as cidades, tanto do ponto de vista das suas instituições públicas quanto dos vários fios que tecem o seu composto social, o conhecimento é um recurso que, se reticularizado, implementa mudanças positivas e "comuns", disponíveis a todos (COLLIER, 2014). Essa aporia anda sendo documentada, sem que haja uma boa solução (CRAIG, 2018).

A percepção da grande maioria dos entrevistados da sociedade civil relata como "boa" a presença e as intervenções do Empreendimento, o que facilita a inferência de que a sua percepção de qualidade de vida é positiva. Esta avaliação deve ser cruzada com a história da definição dos parâmetros de relações de trabalho nas duas cidades, ligados aos ideários da "Marcha para o Oeste" e a naturalização historiográfica do pioneirismo desenvolvimentista (KLEVER, 2016).

Em síntese, os dados coletados apontam para uma correlação entre a entrada da empresa e diversas formas de alteração no tecido socioeconômico dos dois municípios. Mas, mesmo com uma alteração ascendente de indicadores de aceleração, não há muitos indicativos de continuidade em relação ao conhecimento e à sua circulação institucional. Do ponto de vista da dinâmica social, há também uma defasagem de estruturas participativas, para facilitar o enraizamento das iniciativas - sobretudo relacionando a escolaridade e a capacidade de articulação cidadã para exigir accountability por parte da gestão pública, na aplicação equitativa e inteligente dos recursos.

Isso conduz ao outro elemento estrutural constatado e que também se apresenta como uma constante, a fragilidade potencial dos gestores municipais. A precariedade do chamado capital humano, ou seja, a preparação dos gestores para assumirem a tarefa de mediar entre instituições de cidades de pequeno porte, no interior rural e medianamente conectado, e um empreendimento ultraconectado de implicações e recursos macroeconômicos e interesses geopolíticos. Notam-se dificuldades das estruturas municipais, com folha de pagamento inflacionada, investimentos mínimos em áreas estratégicas e histórica dependência das políticas partidárias, situação que gera uma cisão entre a polis/cidadãos, a máquina administrativa municipal e stakeholders de grande impacto. Não se veja aqui desmerecimento das pessoas implicadas na administração, mas a constatação de um desnível entre a especialização dos que chegam e a vulnerabilidade na preparação dos atores territoriais, sem formação específica para lidar com o mercado especulativo e a atividade industrial de grande escala.

\section{ALGUMAS CONSIDERAÇÕES: DA IDEIA DE DESENVOLVIMENTO AO EQUILÍBRIO ENTRE ATORES TERRITORIAIS COMO DEFINIÇÃO DO DESENVOLVIMENTO LOCAL}

Uma representação do desenvolvimento típica da modernidade, já referida como uma espécie de física social, idealiza as atividades caracterizadas como industriais, desvalorizando a industriosidade de atores periféricos - a improvisação e os ritmos mais lentos da vida comum. É gerado e propagado um sentimento de eficiência, que perturba as interlocuções produtivas com atores diretamente envolvidos em processos sociais, que tendem a ser vistos de forma 
esquemática e passiva, a partir de perspectivas analíticas elitizadas e criptografadas por centros de decisão econômica ou política - como anota, por exemplo, Katunarič (2014).

Em países que tiveram um período de colonização longo, como o Brasil, esse tipo de representação espalhou-se em um período histórico que secunda a formação do parque industrial (BRESSER-PEREIRA, 1997). Para a construção da indústria brasileira, as cidades mais isoladas vão sendo representadas como atrasadas, por não participarem do ideal técnico e acumulacionista, tornando-se alvos de iniciativas de intervenção, para que entrem nos trilhos. Isto está documentado em estudos recentes, que mostram um movimento de "estrangeirização" das matrizes tecnológicas e, no caso, de posse de porções importantes do ambiente (SAUER; LEITE, 2012). Uma das possibilidades de se estudar esse hiato que se cria entre escalas de desenvolvimento é a proposta do Desenvolvimento Local, enriquecido de novas contribuições.

O conceito de Desenvolvimento Local enfatiza elementos não imediatamente financeiros para caracterizar os processos de desenvolvimento. Um dos seus insights é a relação entre a interação dos atores territoriais e a reequilibração dos territórios para negociar com movimentos de globalização (BARQUERO, 2002). A força desse campo conceitual deriva de dois elementos: o equilíbrio entre os atores territoriais e a iniciativa endógena. Isso pode ficar mais claro obtendo mais força analítica, ao se lançar mão de uma tipologia dos diversos processos, como a proposta por Ávila (2006).

Segundo ele, a atuação do processo vai variar a partir do possível protagonismo dos seguintes agentes historicamente relevantes: os Estados Nacionais (Desenvolvimento para o Local / DpL); os novos atores que, na modernidade, vêm sendo denominados como empreendedores (Desenvolvimento no Local [DnL]); e, finalmente, os locais (Desenvolvimento Local [DL]). Esta tipologia quase weberiana tem intenção heurística, ou seja, não visa gerar iniciativas centralizadas, mas movimentos de conscientização (RIST, 2014).

\section{a. Desenvolvimento como engenharia social de Estado ou Desenvolvimento para o Local (DpL)}

Os Estados Modernos destacam-se, desde o século XVI, por uma aceleração competitiva em processos de implementação de uma nova forma de vida. Processos como a comunicação, indústria e urbanização deflagram reconfigurações em todos os níveis, criando um estilo de viver e de organizar os territórios que se impõe sobre grande parte do planeta (DÖRRE; LESSENICH; ROSA, 2015). A iniciativa parte das mais altas escalas de poder das Unidades de Estado. Dispõe-se da totalidade do ambiente do país, que vai ser repensado como um conjunto de "recursos", explorados a partir de lógicas variadas. No caso do Brasil, a sua formação econômica foi dependente de outros países de indústria mais elaborada (FRANK, 1969). O Brasil configura-se como produtor de matéria-prima, beneficiada e comercializada por outros parceiros comerciais. Assim foi com o café, a borracha, a laranja, o aço e, mais recentemente com a soja e com a carne. No caso da cana-de-açúcar, tem-se um dos esforços empreendidos para interiorizar o trabalho industrial.

Essa lógica de processar o movimento de conversão do ambiente em produtos aproveitáveis para um sistema de vida (RIST, 2014) concentra poder em instâncias que criam iniciativas e projetos de integração, povoamento, ocupação e exploração de regiões. Criam-se, ainda, iniciativas que alteram a matriz produtiva do país. Essa forma de ação possui a perspectiva de criar uma identidade, e marca comum, que unifica a extensão territorial. É o equivalente à 
situação do monolinguismo (DERRIDA, 1996), que praticamente constitui o Brasil no discurso da Unidade Nacional. O efeito colateral desse modelo é o ideário padronizador das agendas do desenvolvimento, gerando uma homogeneização que sobrevoa diversas fontes de riqueza real da União. Se a matriz única de desenvolvimento é o projeto de alta escala, o Brasil reduz as perspectivas da biodiversidade, da sócio ou da etnodiversidade e torna-se um arremedo de seus colonizadores, ou titereiros.

\section{b. Desenvolvimento como empreendimento ou Desenvolvimento no Local (DnL)}

Outra matriz importante, em concorrência com a primeira, destaca o papel do indivíduo para a construção do tecido social e da riqueza do País. Conceitos fundamentais aqui são os de Empreendedorismo e Inovação (BITTAR; BASTOS; MOREIRA, 2014). O Indivíduo reage ao protagonismo dos agentes políticos de alta escala, alterando o sistema a partir do seu desejo e da sua força social de institucionalizar as suas ideias (CALDEIRA, 2017). Impulsionados pela narrativa linear e euforizante da história da tecnologia, empreendedores vão se consolidando ao longo do tempo, em um arco histórico que aproveita bem as duas guerras mundiais do século XX para criar indústrias de armas, automóveis e de pesquisa toxicológica e nutricional, até chegar ao momento em que poucas empresas detêm grande parte das iniciativas "inovadoras" em relação aos processos, países e territórios. O caso de George Soros é evidente, mas não isolado. Von Rétyi (2016) o apresenta como um modelo típico de empreendedor pós-crise de 2008, um acumulador que leva o esforço especulativo para além dos limites do capital. Na análise da vida de George Soros, ele mostra como esse investidor, principal acionista da Adecoagro, articula o seu interesse de especulação transnacionalizante do capital, com iniciativas de aquisição de ativos ambientais em diversos países cuja legislação permite e que não veem relação entre a alienação de ativos e a soberania nacional. O que no tecido epitelial é uma discussão ambiental é também sintoma de um movimento geopolítico e especulativo.

No caso em epígrafe, trata-se de iniciativa transnacional, de um grupo de empreendimentos de propriedade de um ator territorial que opera ao menos em três países diferentes. Essa operação encontra eco na história anterior do Brasil. André Gunder Frank, em um estudo clássico (1969), reúne a leitura de Celso Furtado da indústria da cana no Nordeste às tendências de compra de ativos para narrar o estabelecimento de uma parceria econômica assimétrica, com a subsequente decadência do parceiro de negociação. As iniciativas individuais surgem em países centrais, tomando corpo - e delimitando a exploração dos corpos e dos gêneros - em países periféricos (Assim MATHUR, 2016; McCANN; McCLOSKEY, 2015; HAY, 2004). Harrison (2010) aponta para grandes categorias que criam um campo de resistência à ação dos territórios e à sua iniciativa. Partindo de grandes agentes, nasce uma iniciativa de engenharia social global, ou seja, da subalternização de parcerias comerciais a interesses mais fortes. Ele afirma que a aquisição de ativos ambientais, para, a partir de iniciativas localizadas, aumentar a produção ao mesmo tempo material e industrial, e a movimentação de capital de bolsa de valores são novas práticas especulativas que constituem uma movimentação que fragiliza os atores locais. Para Hay, essa forma de agir pode ser denominada como "neoliberalismo necessitário" (HAY, 2004, p. 500). Trata-se de uma forma de agir que normaliza a imagem da pequena cidade, isolada e pobre, a ser salva pela criação de emprego e renda ocasionada pelo grande ator que, ademais, vem ajudar a preservar a natureza. 
Nada disso é completamente falso. Mas nada escapa à força motriz que é a geração de ativos em bolsas de capitais. Colin Hay, mesclando análise econômica e crítica de mecanismos retóricos, afirma que, assim, a especulação se substitui à produtividade e às relações de comércio, impondo-se como um dogma, em avançados esquemas de racionalidade. Isso prepara uma crise, pois os ativos que sustentam essa bolha possuem pouca aderência política e são limitados (HAY, 2000; 2004; 2013). O mesmo Hay (2000) afirma que, em vez de uma globalização, existem muitas, que interagem e se entrecruzam até atingir a escala mais alta, a do mercado financeiro e da geopolítica, ou seja, da macroengenharia social.

É evidente que as iniciativas de todos os processos implicados neste modelo são exteriores. Deverão ser contrapostos, pois, por grandes esforços das localidades, "ancorando" aspectos dos empreendimentos e evitando perdas ou desmontes muito graves, quando do seu deslocamento para regiões que considerem mais vantajosas ou menos negativas, por algum motivo social, tributário ou pelo escasseamento de matéria-prima. Nos dois municípios envolvidos, essa questão aparece muito claramente acerca dos dados em relação ao tecido social. A escolaridade na formação da população pouco varia, o que aponta para uma fraca apropriação da empresa pela população local, podendo gerar diversas situações. A mais comum seria a dependência em relação ao agente externo e um descolamento em relação às próprias possibilidades, tornando o território um quase satélite das iniciativas externas. A própria empresa, diante da qualificação das pessoas abaixo das suas expectativas, busca profissionais estratégicos fora da região, passando a usar profissionais locais para funções menos qualificadas.

Esse fenômeno já foi bem individuado e descrito desde a década de 1970, denominado de "industrialização dependente" (FRANK, 1969). O fenômeno em si auspicioso da internacionalização, a irradiação das empresas para além das suas fronteiras, traz consigo a centralização de agenda e de administração que propõe a empresa como uma competidora desigual, uma predadora para campos inexplorados (McCANN; MCCLOSKEY, 2015). O local será um satélite, fornecedor de matéria-prima ou pouco mais que isso (BRESSER-PEREIRA, 1997; HARRISON, 2010). Enquanto a empresa se espalha, detém um núcleo de conhecimentos estratégicos que são alvo de grande segredo e cuidado.

Um caso típico de narrativa que pode ser adaptada à categoria de Desenvolvimento no Local é o texto fundador de Arturo Escobar (1995). Ali articulam-se diversos estratos do encontro colonial, enunciando a produção de uma diferenciação em relação à matriz temporal do tecido social. A percepção dos ritmos de tempo, bem como a da sua finalidade ou teleologia, muda radicalmente, pois a matriz exterior que se interpõe nos cotidianos propõe exigências e padrões, portanto, um sistema de vida que vai alterar padrões e costumes mais ou menos estabilizados anteriormente (ROSA, 2013). Iniciativas de intervenção em sistemas produtivos que alteram o tecido social, econômico e ambiental reforçam modos de relacionar-se que esperam da metrópole as iniciativas, o que se caracteriza como um pensamento subalterno, passivo em relação às iniciativas e à natureza dos recursos (MIGNOLO, 2012). Essa situação pode ser vista de um ponto de vista mais simpático, como um momento a ser superado nas relações entre parceiros (BARQUERO, 2002) ou, de modo crítico, como um programa de criação de relações sociais e econômicas assimétricas (SAUER; LEITE, 2012).

Para que se possa obter uma situação favorável para o parceiro assimetricamente subalterno, deve-se discutir a sua posição em relação ao que Dowbor (2016) denomina de "poder local" e que se constitui como a posse de algumas iniciativas centrais. Tratar-se-ia do surgimento, ou 
da consolidação, de uma ou mais fontes de iniciativa, de ideias, para a determinação de agendas de Desenvolvimento e de estratégias de intervenção. Se as ideias vêm de uma fonte exterior, quando essa fonte se vai, elas desvanecem junto, por não possuírem consistência própria.

\section{c. Iniciativa territorial, endógena, sustentável, escalada: Desenvolvimento Local (DL)}

A crise dos dois modelos acima é evidente e ressaltada por vários autores. Um dos mais novos, que estuda a globalização como processo complexo, é Craig (2018), que observa haver uma crise de grandes proporções a avizinhar-se, de natureza "socioecológica". Trata-se da tensão entre visões de mundo que o consideram como objeto a ser desfrutado, por um lado, e que o contemplam como um organismo a ser fruído, em ritmo mais lento. O encontro dessas - e de outras possíveis - visões está gerando fissuras de grandes proporções.

O movimento intitulado Desenvolvimento Local (DL) possui diversos acentos e apresenta-se com dois grandes grupos de características. Uma característica comum é o traço de resistência diante de projetos econômicos que fracassaram, ou reconfiguração, em escala mais ampla e diversificada, de processos de implantação de empreendimentos. O mais interessante a partir dos dados do caso em questão é o fracasso de iniciativas de inspiração neomarshalliana, de onde nasceram iniciativas de reorganização produtiva na Espanha; trabalhistas, na Inglaterra; e agrícolas, na Itália e depois no Brasil (ÁVILA, 2006). Na medida em que vão acontecendo as relações de implantação e de consolidação de empreendimentos, ou as relações entre grandes empreendimentos e resistências populares, o traço comum mais importante é o surgimento de redes de mediação e negociação que diversificam as matrizes de iniciativa e reforçam a independência dos locais, em relação a centros de autoridade ou recursos. As iniciativas são apropriadas, e os territórios vão se qualificando como centros de "poder" e de iniciativa (DOWBOR, 2016).

O mais importante é a presença de uma rede de parcerias com o eixo da iniciativa estando presente no local, mesmo que a partir de hibridações e de resistências (MIGNOLO, 2012). Outras formas de desenvolvimento podem ser incorporadas como iniciativas, com a condição de que, de alguma forma, o local ganhe densidade e reivindique aos poucos uma posição de protagonismo. No caso de iniciativas que provêm de uma realidade estatal, espera-se uma capilaridade institucional. No caso de iniciativas que provêm do empuxo do mercado, espera-se uma reticularidade sociodinâmica.

Aqui é importante notar que, se por um lado existe a pressão de grandes atores sobre locais menores, ou as territorialidades que se mostram vulneráveis para assumir grandes agendas de relações de troca, por outro lado existe a pervasiva presença de ferramentas globais que permitem mais esforços de localização. Uma das possíveis chaves para se falar em uma melhor qualificação de pequenas cidades, neste contexto, é a tese do papel funcional da imaginação para mobilizar o imaginário através do consumo cultural, atraindo movimentos de requalificação (APPADURAI, 1996). O cenário que a modernidade apresenta exige um papel de prazer ativo no espectador que escolhe diversos modos de interação com os estímulos. Isso também pode ser considerado uma forma de agência, um eixo para desenvolver ações de empoderamento e construção de autonomia. Ou seja, de capacidade para reivindicar uma posição favorável em relações de troca com atores mais aparelhados.

Angélica e Ivinhema fazem parte de um amplo movimento, de escala mundial, de afirmar a ocupação produtiva e a integração regional através de um conjunto de iniciativas ligadas à 
agricultura intensiva e monopolista (TEIXEIRA, 2015), desde a criação de ambos em 1963 (cf. IBGE, 2018a; IBGE, 2018b). Com a entrada em jogo do parceiro ligado ao capital financeiro, a agricultura intensiva e monopolista ganha um novo destaque, torna-se "estrangeirizadora" (SAUER; LEITE, 2012). A própria empresa, encomendando a pesquisa, cai numa duplicidade curiosa. É preciso saber se é um caso de greenwashing, legitimação de práticas através da retórica da ética e da sustentabilidade, ou se seria um caso de opção por princípios de cidadania num projeto de ocupação e desenvolvimento, iniciando um novo ciclo de responsabilidade corporativa (BOWEN, 2014).

Não se avalia aqui a capacidade moral ou a intenção de atores. Sobre o palco institucional, eles basicamente atualizam desejos e possibilidades, agem de forma mais ou menos inteligível, cada um a partir de sua pauta. No entanto, é um fato importante que a verdadeira parceria se dá entre iguais. As assimetrias, comuns nos processos de desenvolvimento, e que dão azo à redução de territórios ao status de colônias, servem para reforçar a desigualdade de condições nas capacidades de troca, o que, para Mignolo (2012), possui um componente vital, a subalternização. As relações de comércio são, historicamente, pontos de aparecimento de grandes problemas e tendências de relacionamento entre seres humanos. Como se estabelecem as relações de troca, estabelecem-se também espacialidades, identidades, capacidades de agência e hierarquias de protagonismos. Se um ator que entra em contato com outro interessa-se apenas por um produto marginal em relação à sua capacidade, estabelece-se uma relação de subalternidade, na medida em que o primeiro força o segundo a permanecer na posição de fornecedor de matéria-prima e de trabalho menos qualificado, enquanto o outro, com mais capacidade de articulação, dita quase todas as regras do relacionamento. Para o ator de menor escala, sobra o limite do esgarçamento da pele. O conhecimento limitado, nas duas pequenas cidades, não é uma questão menor. Pode ser o início da pergunta pela possibilidade de esses atores terem ou não capacidade de analisar as questões que decidam ser importantes, tornando-se protagonistas das próprias capacidades de negociação com outros parceiros.

\section{NOTAS FINAIS}

A entrada no país de grandes empresas, como é o caso da Adecoagro, obedece à lógica do "investimento direto" (SILVA FILHO, 2015). A dinâmica espelha o passado, mas o complica (VALENCIA, 2017). O ator de grande escala que compra ativos não quer nem pode ver o território como um sistema de parceiros e interlocutores, porque entre eles existe uma fundamental assimetria (PFETSCH; LANDAU, 2000). Kunibert Raffer (1987), na consideração das relações entre grandes atores econômicos e suas relações com territorialidades mais frágeis, aponta que as relações que acontecem com interferência minorada dos Estados nacionais são de natureza agressiva, pois os hospedeiros não possuem condições de mediar o volume de recursos e desejos que irrompem em ritmo diferente do seu. Isso cria um hiato que aprofunda a desigualdade e as arritmias.

Essa assimetria demonstra-se em todo o sistema de relações de comércio, regulamentado a partir de outras escalas para além da municipalidade, que se encontra com uma capacidade de argumentação e de reivindicação frágil, e apoiado por programas do Governo Federal. O que gera diversos impactos, sobretudo sobre a capacidade de continuar esse processo de negociação pelo qual um ponto no mapa se constrói como uma territorialidade, ou seja, como sujeito coletivo de interesses, direitos e deveres, no contexto de relações comerciais, como parece ser 
o objetivo mais importante dos primeiros pensadores das teorias do "Desenvolvimento Local" (BARQUERO, 2002, Cf. também BELLINGIERI, 2017). Entrementes, especialistas em macroeconomia lideram um processo de naturalização, apresentando como positiva a entrada de grande fluxo de capital (SILVA FILHO, 2015; GARCIA; LIMA; VIEIRA, 2015). Ocorre que o preço do lucro episódico é a venda de ativos territoriais, perpetuando uma situação de irregularidade no sistema jurídico e produtivo e acirrando o esgarçamento do tecido social. Do ponto de vista das relações de troca, a capacidade argumentativa do parceiro menor vai se transformando em silêncio e esquecimento. Isso se encontra documentado sob rubricas como a das desigualdades regionais (ARAÚJO; SANTOS, 2009) ou a das relações entre terra e mão de obra (DELGADO, 2009). Uma reflexão que aprecie as iniciativas associativas, em contraste com a consideração das assimetrias sob o ponto de vista de uma economia política crítica, mostrará que, se falha a iniciativa local, não há perspectivas de equilibração no progresso e aumento de indicadores (DOWBOR, 2016; ÁVILA, 2006; HEROD, 2011).

Mais acima, apontou-se para uma tipologia no esforço teórico do Desenvolvimento Local, que dá conta do maior problema que o relatório diagnosticou, que parece ser a pouca capacidade de as cidades levarem iniciativas para a frente sem o suporte da Empresa. Isso configura um caso de "Desenvolvimento no Local" (DnL). Ora, este "Desenvolvimento" não atende à matriz produtiva local que, essencialmente, permanece em relação subalterna. Mas, apesar das notas críticas a propósito dos impactos negativos de projetos de Desenvolvimento capitaneados por grandes empresas, deve-se acrescentar uma anotação importante.

Parte-se de um fato, historicamente comprovado, que mostra a importância da tensão entre agentes industriosos do território, organizados em mais de uma escala de relações e linguagens sociais e culturais. Ou seja, quanto mais fortes as relações, mais consolidado será o sistema. Um exemplo será a sua consideração no nível micro (pessoas, empreendimentos de pequena escala e alcance capilar), meso (instituições políticas, associações e cooperativas, redes de relações de circuito mais curto) e macro (articulações com autoridades relacionadas ao sistema político vigente, que conferem circuito longo e visibilidade jurídica e comercial, além de atores de grande escala). No interior do Brasil, ocorre um hiato e uma deficiência grave na articulação entre atores socioterritoriais e atores políticos (RADOMSKY, 2013; RIGON; SANT'ANA, 2013). Pode-se tentar explicar esse fenômeno partindo de várias hipóteses: traços da situação colonial; imensidade do território; complexidade do sistema social em relação de crise com o sistema político. Como seja, o fato é que as instituições (no caso, municipalidades e atores relacionados) não constroem articulações suficientes para sustentar os processos simultâneos que envolvem os diversos atores. No caso em epígrafe, trata-se, por um lado, de um ator individual projetado em escala multinacional. Por outro lado, a capilaridade típica do sistema territorial, com suas tintas particulares do interior do Centro-Oeste brasileiro: formação multiétnica e escolaridade baixa; passado escravagista e relações sociais marcadas por esse patrimônio tácito; abundância de terra, sol e água, em um sistema de relações agrárias ineficiente.

Ou seja, a própria relação entre dois atores assimétricos potencializa a agressividade do empreendimento. Seria necessária uma iniciativa ampla de fortalecimento dos atores locais, adensando a função da municipalidade, dos agentes "públicos". Sem responsabilizar os atores individuais, uma das partes, minguada, desequilibra as outras duas. Sem a articulação interpelante das instituições públicas, uma empresa que ingressa na escala local já sob alta pressão do mercado mais global torna-se um predador. Por outro lado, o ator de pequena escala, sem mediações, 
torna-se passivo por uma questão de sobrevivência. Como salientam Bessa (2005) e também Osmar Rigon e Thiago Sant'Ana (2013), as cidades brasileiras que medeiam entre os contextos urbano e rural tendem a sofrer uma mudança de escala na medida em que se espraiam nas dinâmicas regionais. O que deve acontecer nos dois casos aqui examinados é a melhor estruturação da mão de obra, para a maior capacitação produtiva, por um lado, e, mais que isso, o fortalecimento da aptidão mediadora das instituições municipais, para que se tornem efetivamente capazes de protagonizar as próprias iniciativas de desenvolvimento, minorando a sua dependência de atores externos. Isto deve ser assunto para investigações ulteriores, trazendo a cultura mais perto dos direitos humanos, em sua articulação com a fábrica da cidadania altiva e produtiva, mesmo economicamente. Mas, sobretudo, consolidando a criatividade das instituições territoriais.

\section{REFERÊNCIAS}

AGUILERA URQUIZA, Antonio Hilário (Coord.). Estudo sociocultural e econômico sobre a realidade atual dos municípios de Ivinhema e Angélica e projeções sobre os impactos do empreendimento ADECOAGRO na região. Campo Grande, MS: Fundação Universidade Federal de Mato Grosso do Sul, nov. 2014. 53 p.

APPADURAI, Arjun. Modernity at large. Cultural dimensions of globalization. Minneapolis and London: University of Minnesota Press, 1996.

ARAÚJO, Tania Bacelar; SANTOS, Valdeci Monteiro. Desigualdades regionais e Nordeste em "Formação Econômica do Brasil". In: ARAÚJO, Tarcísio Patricio; VIANNA, Salvador Teixeira Werneck; MACAMBIRA, Júnior (Org.). 50 anos de "Formação Econômica do Brasil". Ensaios sobre a obra clássica de Celso Furtado. Rio de Janeiro: IPEA, 2009. p. 177-200.

ÁVILA, Vicente Fideles de. Cultura de Sub/Desenvolvimento e Desenvolvimento Local. Sobral: UVA, 2006.

BARQUERO, Antonio Vásquez. Desenvolvimento endógeno em tempos de globalização. Porto Alegre: Fundação de Economia e Estatística, 2002.

BRASSIER, Ray. Prometheanism and its critics. In: MACKAY, Robin; AVANESSIAN, Armen (Org.). Accelerate. The accelerationism reader. Falmouth, UK: Urbanomic, 2014. p. 467-88.

BELLINGIERI, Julio Cesar. Teorias do desenvolvimento regional e local: uma revisão bibliográfica. Revista de Desenvolvimento Econômico-RDE, Salvador, ano XIX, v. 2, n. 37, p. 6-34, ago. 2017.

BESSA, Kelly Cristine. Reestruturação da rede urbana brasileira e cidades médias: o exemplo de Uberlândia (MG). Caminhos de Geografia, cidade, v. 24, n. 6, p. 268-88, out. 2005. Disponível em: http://www.ig.ufu. $\mathrm{br} / \mathrm{revista/caminhos.html.} \mathrm{Acesso} \mathrm{em:} 15$ fev. 2018.

BITTAR, Fernando Shigueo Omoto; BASTOS, Livia Tiemi; MOREIRA, Vivian Lemes. Reflexões sobre o empreendedorismo: uma análise crítica na perspectiva da economia das organizações. Revista de Administração da UFSM, Santa Maria, v. 7, n. 1, p. 65-80, mar. 2014.

BOWEN, Francis. After Greenwashing: symbolic Corporate Environmentalism and Society. Cambridge, UK: Cambridge University Press, 2014.

BRESSER-PEREIRA. Luis Carlos. Economia brasileira: uma introdução crítica. São Paulo: Edições 34, 1997.

CALDEIRA, Jorge. História da riqueza no Brasil: Cinco séculos de pessoas, costumes e governos. São Paulo: Estação Brasil, 2017. 
COLLIER, David. Think like a commoner: a short introduction to the life of the commons. Gabriola Island, Canada: New Society Publisher, 2014.

CRAIG, Martin. On 'The Other Crisis': Diagnosing the socio-ecological crisis. In: HAY, Colin; HUNT, Tom (Ed.). The coming crisis. Sheffield, UK: Palgrave Macmillan, 2018. p. 17-24.

DELGADO, Guilherme. Terra e mão de obra em "Formação econômica do Brasil". In: ARAÚJO, Tarcísio Patricio; VIANNA, Salvador Teixeira Werneck; MACAMBIRA, Júnior (Org.). 50 anos de "Formação Econômica do Brasill": Ensaios sobre a obra clássica de Celso Furtado. Rio de Janeiro: IPEA, 2009. p. 229-45.

DERRIDA, Jacques. Le monolinguisme de l'autre ou la prothèse d'origine. Paris: Galilée, 1996.

DÖRRE, Klaus; LESSENICH, Stephan; ROSA, Hartmut (Org.). Sociology, capitalism, critique. London; New York: Verso, 2015.

DOWBOR, Ladislau. Poder Local. Imperatriz, MA: Etica, 2016.

EISENSTADT, Samuel. Tradition, change, and modernity. New York: Wiley, 1973.

ESCOBAR, Arturo. Encountering development: the making and unmaking of the third world. 3. ed. Princeton, NJ: Princeton University Press, 1995.

FAIRCLOUGH, Isabella; FAIRCLOUGH, Norman. Political discourse analysis: a method for advanced students. London; New York: Taylor and Francis, 2012.

FRANK, André Gunder. Capitalism and Underdevelopment in Latin America: historical Studies of Chile and Brazil. New York; London: Monthly Review Press, 1969.

FREITAS, Elisa Pinheiro de; ROSSINI, Rosa Ester; QUEIRÓS, Margarida. O poder das empresas transnacionais sobre o território brasileiro. Reflexões a partir do sector sucroenergético. In: COLOQUIO INTERNACIONAL DE GEOCRÍTICA EL CONTROL DEL ESPACIO Y LOS ESPACIOS DE CONTROL, 13., Barcelona, 5-10 de maio de 2014. Anais [...]. Barcelona, 2014. p. 1-21.

GARCIA, Junior Ruiz; LIMA, Divina Aparecida Leonel Lunas; VIEIRA, Adriana Carvalho Pinto. A nova configuração da estrutura produtiva do setor sucroenergético brasileiro: panorama e perspectivas. Revista de Economia Contemporânea. Rio de Janeiro, v. 19, n. 1, p. 162-84, jan./abr., 2015.

HARRISON, Graham. Neoliberal Africa. The Impact of Global Social Engineering. London; New York: Zed Books, 2010.

HAY, Colin. The normalizing role of rationalist assumptions in the institutional embedding of neoliberalism. Economy and Society, v. 33, n. 4, p. 500-27, 2004.

HAY, Colin; MARSH, David (Ed.). Demystifying globalization. London: Macmillan Press, 2000.

HAY, Colin. The failure of anglo-liberal capitalism. Basingstoke: Palgrave Macmillan, 2013.

HEROD, Andrew. Scale. Abingdon, Oxon, UK.: Routledge, 2011. 294 p.

INSTITUTO BRASILEIRO DE GEOGRAFIA E ESTATÍSTICA (IBGE). O Brasil em síntese - Municípios: Angélica. IBGE, [s.d.]. Disponível em: https://cidades.ibge.gov.br/brasil/ms/angelica/panorama. Acesso em: 16 fev. 2018. 
INSTITUTO BRASILEIRO DE GEOGRAFIA E ESTATÍSTICA (IBGE). O Brasil em Síntese - Municípios: Ivinhema. IBGE, [s.d.]. Disponível em: https://cidades.ibge.gov.br/brasil/ms/ivinhema/panorama. Acesso em: 16 fev. 2018.

KATUNARIČ, Vjeran. Evolution, globalization and developmental hybrids. Teorija in Praksa, v. 51, número especial, p. 107-30, 2014.

KLEVER, Lucas de Oliveira. Passado e Presente: Projeto político e escrita da história na marcha para oeste. In: ENCONTRO DE PESQUISAS HISTÓRICAS, 3., Porto Alegre. Anais [...]. Porto Alegre: PPGH/PUCRS, 2016. p. 217-28. Disponível em: www.ephispucrs.com.br. Acesso em: 17 fev. 2018.

MATHUR, Hari Mohan (Ed.). Assessing the social impact of development projects. Experience in India and other Asian Countries. New Delhi: Springer, 2016.

McCANN, Gerard; McCLOSKEY, Stephen (Ed.). From the local to the global. Key issues in development studies. London: Pluto Books, 2015.

MIGNOLO, Walter D. Local histories/global designs: coloniality, subaltern knowledges, and border thinking. Princeton, NJ: Princeton University Press, 2012.

PEET, Richard; HARTWICK, Elaine. Theories of development. Contentions, arguments, alternatives. New York; London: The Guilford Press, 2015. Third Edition.

PEREIRA, Eliane M. C. Manso. O estado novo e a marcha para o oeste. História Revista, Goiânia, v. 2, n. 1, p. 113-29, jan./jun., 1997.

PFETSCH, Frank R.; LANDAU. Alice, Symmetry and asymmetry in international negotiations. International Negotiation 5, Amsterdam: Kluwer Academic, 2000, p. 21-42.

PIETERSEE, Jan Nederveen. After post-development. Third World Quarterly, v. 21, n. 2, p. 175-91, abr. 2000.

RADOMSKY, Guilherme Francisco Waterloo. Pós-desenvolvimento, indicadores e culturas de auditoria: reflexões críticas sobre governança e desenvolvimento. Ciências Sociais Unisinos, v. 49, n. 2, p. 155-63, maio/ago. 2013.

RAFFER, Kunibert. Unequal exchange and the Evolution of the World System. Reconsidering the impact of trade in the North-South relations. New York: Palgrave Macmillan, 1987.

RIGON, Osmar; SANT'ANA, Thiago César Frediani. Os papéis das pequenas cidades no contexto atual da rede urbana brasileira: um ensaio sobre a região da AMUSEP. Revista Percurso - NEMO, Maringá. v. 5, n. 1, p. 157-77, 2013.

RIST, Gilbert. The story of development. From western origins to global faith. 3. ed. Tradução de Patrick Camiller. London; New York: Zed Books, 2014.

ROSA, Hartmut. Social acceleration. A new theory of modernity. New York, Chichester, West Sussex: Columbia University Press, 2013.

SAUER, Sergio; LEITE, Sergio Pereira. Expansão agrícola, preços e apropriação de terra por estrangeiros no Brasil. RESR, Piracicaba, v. 50, n. 3, p. 503-24, jul./set. 2012.

SILVA FILHO, Edison Benedito. Trajetória recente do investimento estrangeiro direto e em carteira no Brasil. Boletim de economia e política internacional BEPI, n. 19, p. 5-20, jan./abr. 2015. 
TEIXEIRA, Jodenir Calixto. Os efeitos socioespaciais da expansão canavieira na bacia hidrográfica do Rio Ivinhema no Estado de Mato Grosso do Sul. 2015. Tese (Doutorado em Geografia)- Universidade Estadual Paulista, Presidente Prudente, SP, 2015.

VALENCIA, Adrián Sotelo. Sub-imperialism revisited. Dependency theory in the thought of Ruy Mauro Marini. Leiden and Boston: Brill, 2017. p. 131-50.

VALLEJO-ALONSO, Belén; RODRÍGUEZ-CASTELLANOS, Arturo; ARREGUY-AVASTUY, Gerardo (Ed.). Identifying, measuring, and valuing knowledge-based intangible assets: New perspectives. Hershey and New York: Business Science Reference, 2011.

VILLAS BÔAS, Orlando; VILLAS BÔAS. Cláudio, A marcha para o oeste. A epopeia da expedição RoncadorXingu. São Paulo: Companhia das Letras, 2012.

VON RÉTYI, Andreas, Georges Soros. Der Multimilliardär, sein Globales Netzwerk und das Ende der Welt, wie wir sie kennen. Rottemburg: Kopp Verlag, 2016.

\section{Sobre os autores:}

Antonio Hilário Aguilera Urquiza: Doutor em Antropologia e Master em Educação (Tecnologias de la Educación) pela Universidade de Salamanca-Espanha. Mestre em Educação (Educação Indígena) pela Universidade Federal de Mato Grosso. Especialista em Antropologia (teoria e métodos). Graduado em Filosofia pela Faculdade de Filosofia, Ciências e Letras de Lorena, em Teologia pelo Instituto de Teologia de São Paulo, e em Pedagogia pela Universidade de Cuiabá (1994). Professor adjunto da UFMS e da Pós-Graduação em Antropologia Social (UFMS), assim como da Pós-Graduação em Direitos Humanos (FADIR/UFMS). E-mail: hilarioaguilera@gmail.com, Orcid: http:/orcid.org/0000-0002-3375-8630

Josemar de Campos Maciel: Doutor em Psicologia pela Pontifícia Universidade Católica de Campinas. Mestre em Teologia Sistemática pela Pontifícia Universidade Gregoriana de Roma, e em Psicologia pela Universidade Católica Dom Bosco. Graduado em Filosofia pelas Faculdades Unidas Católicas do Mato Grosso, e em Teologia pela Pontifícia Universidade Gregoriana de Roma. Docente do Programa de Pós-Graduação Stricto Sensu em Desenvolvimento Local da Universidade Católica Dom Bosco (UCDB), do Master in Territorial Development Erasmus Mundus e professor do curso de Licenciatura em Filosofia da UCDB. E-mail: maciel50334@yahoo.com.br, Orcid: http://orcid.org/0000-0001-8277-9422 
